\title{
A ruthenium-based catalyst on carbon electrodes for electrochemical water splitting
}

Lin Li, ${ }^{[a, b]}$ Biswanath Das, ${ }^{[b]}$ Ahibur Rahaman, ${ }^{[b]}$ Andrey Shatskiy, ${ }^{[c]}$ Fei Ye, ${ }^{[d]}$ Peihong Cheng, ${ }^{[\mathrm{a}]}$ Chunze Yuan, ${ }^{[\mathrm{a}]}$ Zhiqi Yang, ${ }^{\mathrm{a}]}$ Oscar Verho, ${ }^{[\mathrm{b}]}$ Markus D. Kärkäs, ${ }^{[\mathrm{c}]}$ Joydeep Dutta, ${ }^{[\mathrm{d}]}$ Tsu-Chien Weng, ${ }^{[a]}$ and Björn Åkermark*[b]

[a] Dr. L. Li, Dr. P. Cheng, Dr. C. Yuan, Z. Yang, and Prof. T. Weng

School of Physical Science and Technology, ShanghaiTech University, Shanghai 201210, China.

E-mail: lilin1@ shanghaitech.edu.cn

[b] Dr. L. Li, Dr. B. Das, Dr. A. Rahaman, Dr. A. Shatskiy, Dr. O. Verho, and Prof. B. Åkermark

Department of Organic Chemistry, Arrhenius Laboratory Stockholm University, Svante Arrhenius v-g 16C, 10691 Stockholm, Sweden

E-mail: bjorn.akermark@su.se

[c] Dr. A. Shatskiy, Prof. Markus D. Kärkäs

Department of Chemistry, KTH Royal Institute of Technology, Stockholm SE-100 44, Sweden.

[d] Dr. F. Ye, Prof. J. Dutta

Department of Applied Physics, Functional Materials, KTH Royal Institute of Technology, 10691

Stockholm, Sweden

\begin{abstract}
Electrochemical water splitting constitutes one of the most promising strategies for converting water into hydrogen-based fuels, and this technology is predicted to play a key role in our transition towards a carbon-neutral energy economy. To enable the design of costeffective electrolysis cells based on this technology, new and more efficient anodes with augmented water splitting activity and stability will be required. Herein, we report an active molecular Ru-based catalyst for electrochemically-driven water oxidation and two simple methods for preparing anodes by attaching this catalyst onto multi-walled carbon nanotubes. The anodes modified with the molecular catalyst were characterized by a broad toolbox of microscopy and spectroscope techniques, and interestingly no $\mathrm{RuO}_{2}$ formation was detected during electrocatalysis over $4 \mathrm{~h}$. These results demonstrate that the herein presented strategy can be used to prepare anodes that rival the performance of state-of-the-art metal oxide anodes.
\end{abstract}




\section{Introduction}

Conversion of solar energy into hydrogen-based fuels is considered to be one of the most promising alternatives to fossil fuels. ${ }^{1}$ Water is an inexpensive and readily available natural source of hydrogen, which has made electrochemical water splitting an intensively pursued research field in the recent decades. ${ }^{2}$ However, the anodic reaction that leads to the oxidation of water to molecular oxygen is plagued by a high activation barrier, which has steered research towards the development of active and durable water oxidation catalysts (WOCs). ${ }^{3}$ So far, the most intensively studied type of catalysts are the molecular ones, which have the advantage of straightforward structural modification and electronic control., ${ }^{4,5}$ However, molecular catalysts generally suffer from limited stability, which in many cases can be improved through attachment of the catalysts onto conductive surfaces, where bimolecular decomposition pathways are impeded by restricted translational mobility. ${ }^{6}$

Catalysts based on $1^{\text {st }}$ row transition metals are considered to be more attractive for large scale industrial applications compared to their $2^{\text {nd }}$ and $3^{\text {rd }}$ row counterparts due to their low cost and environmentally benign character. ${ }^{7-9}$ However, in practice, higher stability and catalytic efficiency have been observed for ruthenium $(\mathrm{Ru})$ and iridium (Ir)-based catalysts, which have made them the most widely studied. ${ }^{10-14}$ Recently, we reported a highly active Rubased water oxidation catalyst, $\left[\mathrm{Ru}(\mathrm{mcbp})(\mathrm{py})_{2}\right]\left(\mathrm{mcbp}^{2-}=2,6\right.$-bis(1-methyl-4-(carboxylate)benzimidazol-2-yl)pyridine, $\mathbf{1}$ in Figure 1). ${ }^{15}$ This catalyst shows an impressive maximum turnover frequency $\left(\mathrm{TOF}_{\max }\right.$ ) of approximately $40000 \mathrm{~s}^{-1}$ (calculated from the foot-of-thewave analysis) at $\mathrm{pH} 9.0,{ }^{16}$ which shares the world record in efficiency with a related catalyst developed by Llobet and co-workers. ${ }^{17}$ Given the remarkable performance of this catalyst, we became interested in immobilizing it on an electrode for application in electrocatalytic water oxidation.

Today, there exists a wide range of strategies for attaching molecular catalysts onto metal oxide electrodes. ${ }^{18,19}$ One of the most common approaches involve the utilization of either phosphonate or carboxylate anchoring groups. ${ }^{20}$ However, a major limitation of these systems is their instability during electrochemical oxidation in alkaline aqueous electrolytes. ${ }^{21}$

Multi-walled carbon nanotubes (MWCNTs) have also been studied as a support for molecular catalysts, and they have shown great promise for improving catalytic performance thanks to their high conductivity and large electrochemically active surface area. ${ }^{22}$ Here, previous approaches to anchor water oxidation catalysts onto MWCNTs have involved modified ligands serving as linkers, ${ }^{23}$ containing mostly aromatic or polyaromatic moieties ${ }^{24}$ 
that can interact non-covalently with the surface of carbon nanotubes via $\pi$-stacking and electrostatic interactions. ${ }^{25-27}$ However, equipping water oxidation catalysts with aromatic or polyaromatic moieties is relatively complicated, which hinders large-scale synthesis and the application of such catalysts.

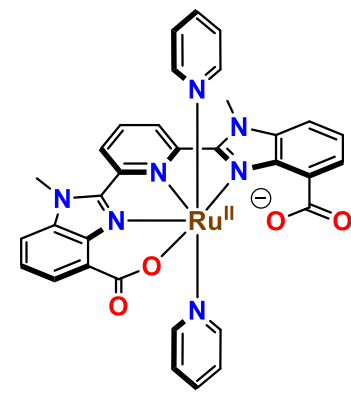

$\mathrm{Ru}^{\prime \prime}(\mathrm{mcbp})(\mathrm{py})_{2}$

1

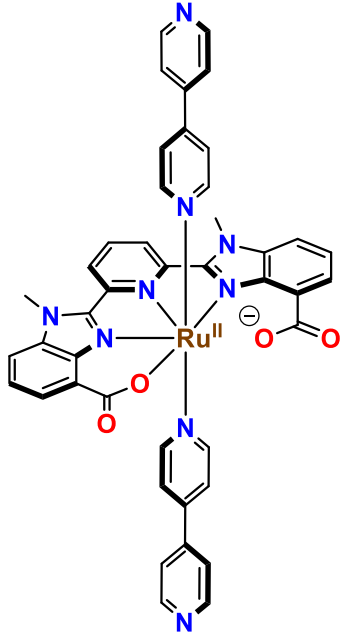

$\mathrm{Ru}^{\prime \prime}(\mathrm{mcbp})\left(4,4^{\prime}-\mathrm{bpy}\right)_{2}$ 2

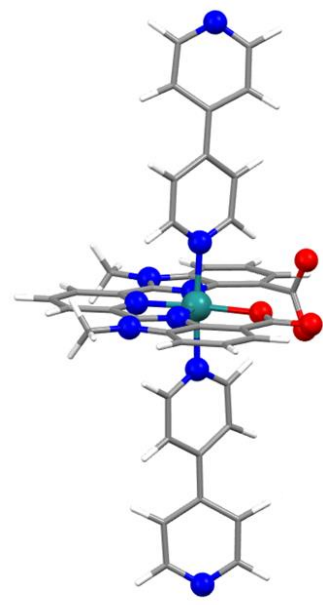

calculated structure for $\mathrm{Ru}^{\prime \prime}(\mathrm{mcbp})\left(4,4^{\prime}-\mathrm{bpy}\right)_{2}$

Figure 1. Chemical structure of the recently reported Ru-based catalyst $\mathbf{1},{ }^{15}$ structure of Rubased catalyst 2 (this work), and optimized by unrestricted DFT calculations structure of 2 (for cartesian coordinates, see the supporting information) in aqueous medium (smd model). ${ }^{28}$ Blue, red, grey and turquoise colors represent nitrogen, oxygen, carbon and ruthenium atoms, respectively.

Herein, we report the synthesis of catalyst $\left[\mathrm{Ru}(\mathrm{mcbp})\left(4,4^{\prime}-\mathrm{bpy}\right)_{2}\right](\mathbf{2})$ and two methods for conveniently attaching it onto MWCNTs. [Ru(mcbp)(4,4'-bpy $\left.)_{2}\right]$ (2) represents a structural modification of the catalyst $\left[\mathrm{Ru}(\mathrm{mcbp})(\mathrm{py})_{2}\right](\mathbf{1})$, in which the two axial pyridine ligands are replaced by 4,4'-bipyridines. This structural modification was shown to greatly improve the interaction between catalyst 2 and the MWCNTs, while not altering the catalytic features of the catalyst significantly. 4,4'-Bipyridine linkers have previously been reported to serve as bridges between a series of metal centers to give coordination polymers. ${ }^{29}$ In an analogous fashion, we prepared the corresponding coordination polymer of $\mathbf{2}$ and directly anchored it onto the MWCNTs. In this work, we describe the synthesis of the new catalyst 2 and its characterization under homogeneous and heterogeneous (after attachment to MWCNTs) conditions. Furthermore, the structural features of catalyst $\mathbf{2}$ on MWCNTs before and after electrolysis on the electrodes were investigated. 


\section{Results and Discussion}

Catalyst 2 was synthesized following a step-wise procedure (for details, see the supporting information, $\mathrm{SI}$ ), initiated by refluxing a mixture of $\mathrm{H}_{2} \mathrm{mcbp}$, [ $\left.\mathrm{Ru}(\mathrm{DMSO})_{4} \mathrm{Cl}_{2}\right]$ and triethylamine in ethanol-water (1:1) and followed by addition of two equivalents of 4,4'-bpy. Continuous reflux of the reaction mixture at $90{ }^{\circ} \mathrm{C}$ over 7 days under $\mathrm{N}_{2}$ atmosphere resulted in precipitation of the major product (Figure S1 and S2). The selectivity of the reaction towards formation of the monomeric complex $\mathbf{2}$ could be improved by following an alternative step-wise procedure, in which $\mathrm{H}_{2}$ mcbp and $\left[\mathrm{Ru}(\mathrm{DMSO})_{4} \mathrm{Cl}_{2}\right.$ ] were refluxed in ethanol-water $(1: 1)$ for $4 \mathrm{~h}$, followed by addition of triethylamine and two equivalents of 4,4 'bpy and continued reflux for 3 days. The monomeric complex 2 was characterized by Nuclear Magnetic Resonance (NMR), High Resolution Mass Spectrometry (HRMS), and UltravioletVisible (UV-Vis) spectroscopy (for details, see the SI). The ${ }^{1} \mathrm{H}$ NMR spectrum of 2 shows a singlet at $\delta 4.48 \mathrm{ppm}$ integrating to $6 \mathrm{H}$ belonging the two methyl groups, and all aromatic protons are present within the $7.48-8.73 \mathrm{ppm}$ range (Figure S1). The presence of the two bipyridine units in $\mathbf{2}$ was further confirmed by HRMS, demonstrating a singly-charged $\mathrm{Ru}-$ complex at m/z 862.1424 (Figure S3) with a characteristic isotope pattern. Several attempts to obtain single crystals of $\mathbf{2}$ suitable for X-ray diffraction analysis were unfortunately unsuccessful. A DFT optimized [B97D3/def2tzvp-6-31G(d,p), aqueous medium (smd model), unrestricted] structure of $\mathbf{2}$ (Figure 1) reveals that the neutral molecule has one free carboxylate and one ruthenium bonded carboxylate unit (for the cartesian coordinates, see the $\mathrm{SI}$ ). The $\mathrm{Ru}-\mathrm{N}$ (benzimidazole) bond distance is significantly shorter at the side where the carboxylate unit is coordinated $(\sim 1.93 \AA)$ compared to the side where it remains as free carboxylate $(\sim 2.15 \AA$ ) unit (Figure $\mathrm{S} 10$ ). The other three $\mathrm{Ru}-\mathrm{N}$ (to the central pyridine and two axial bipyridine ligands) bond distances are between 1.95 and $2.08 \AA$. Attempts to optimize the structure of $\left[\mathrm{Ru}^{\mathrm{II}}(\mathrm{mcbp})\left(4,4^{\prime}-\mathrm{bpy}\right)_{2}\right]$ (2) with both carboxylates coordinated to the ruthenium center did not result in a feasible structure. The UV-Vis spectra of complexes $\mathbf{1}$ and 2 in aqueous phosphate buffer solutions at $\mathrm{pH} 2.0$ and 7.0 displayed metal-to-ligand charge-transfer $\left(\right.$ MLCT) bands $\left(\lambda_{\max } \sim 490-510 \mathrm{~nm}\right)$ that are typical for $\mathrm{Ru}^{\mathrm{II}}$ polypyridine complexes (Figure S4). 

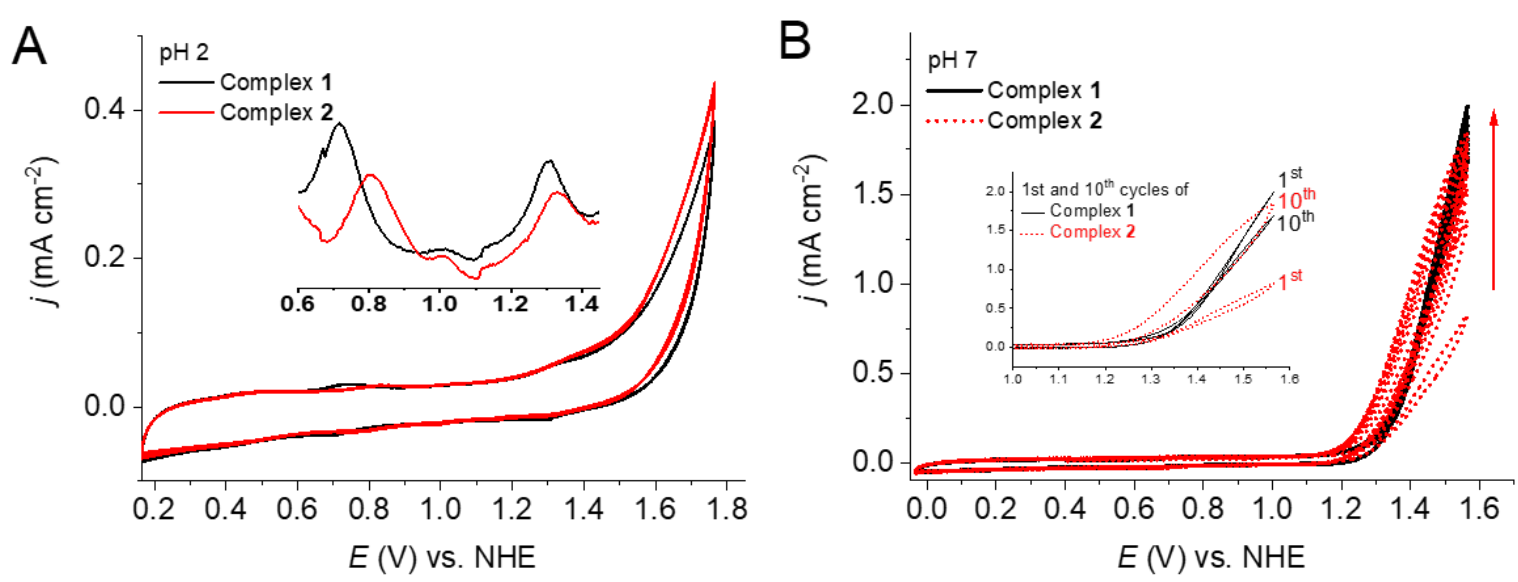

Figure 2. CV and DPV measurements (inset A) of $0.1 \mathrm{mM}$ solutions of complexes $\mathbf{1}$ and $\mathbf{2}$ at pH 2.0 (A) and pH 7.0 (B). Inset B shows the first and the tenth CV cycles. The scan rate for $\mathrm{CV}$ measurements is $100 \mathrm{mV} / \mathrm{s}$. The glassy carbon disk, a Pt disk and $\mathrm{Ag} / \mathrm{AgCl}$ electrodes were used as working, counter, and reference electrodes, respectively.

The cyclic voltammograms (CV) of both $\mathbf{1}$ and $\mathbf{2}$ showed two quasi-reversible waves between 0.60 to $1.45 \mathrm{~V}$ vs NHE in $\mathrm{pH} 2.0$ phosphate buffer (Figure 2A), which can be attributed to the $\mathrm{Ru}^{\mathrm{III}} / \mathrm{Ru}^{\mathrm{II}}$ and $\mathrm{Ru}^{\mathrm{IV}} / \mathrm{Ru}^{\mathrm{III}}$ redox couples. Differential pulse voltammetry (DPV) demonstrated the redox potentials for these couples at 0.72 and $1.3 \mathrm{~V}$ vs NHE for $\mathbf{1}$ and 0.81 and $1.33 \mathrm{~V}$ vs NHE for 2 . These redox waves are followed by an irreversible anodic wave characteristic of water oxidation. The similar CV behavior for $\mathbf{1}$ and $\mathbf{2}$ indicates that the change of ligand from pyridine to 4,4'-bipyridine did not cause any significant differences in the electrochemical behavior at $\mathrm{pH} 2.0$. At $\mathrm{pH} 7,1$ showed slightly lower (around $70 \mathrm{mV}$ ) overpotential for water oxidation in the first scan and the catalytic current remained relatively unchanged during multiple CV scans (Figure 2B). Interestingly, in the case of 2, the electrocatalytic wave continuously increased upon sequential CV cycling, while the onset potential gradually shifted towards more negative potentials. After ten consecutive scans, the catalytic current almost doubled and considerable water oxidation beginning at ca. $1.21 \mathrm{~V}$ vs. NHE could be observed. After ten scans, both of the electrodes (in the presence of $\mathbf{1}$ and 2) were removed, washed with water, and dried. These electrodes were then tested again as the working electrodes in phosphate buffer solutions at $\mathrm{pH} 7.0$ without any additional catalysts (Figure S5). The modified electrodes generated during the electrochemical experiment with 2 showed more than ten times higher catalytic current in comparison to the electrode with $\mathbf{1}$, suggesting greater accumulation of the catalyst on the electrode surface during the CV experiment with 2 (Figure S5) and better interaction of the bipyridine units of 2 with the 
electrode's surface. These results suggested that $\mathbf{2}$ represents a better candidate for heterogeneous water splitting. Upon continuous CV cycling, the catalytic current using both electrodes steadily decreased, indicating detachment of the catalysts from the surface.

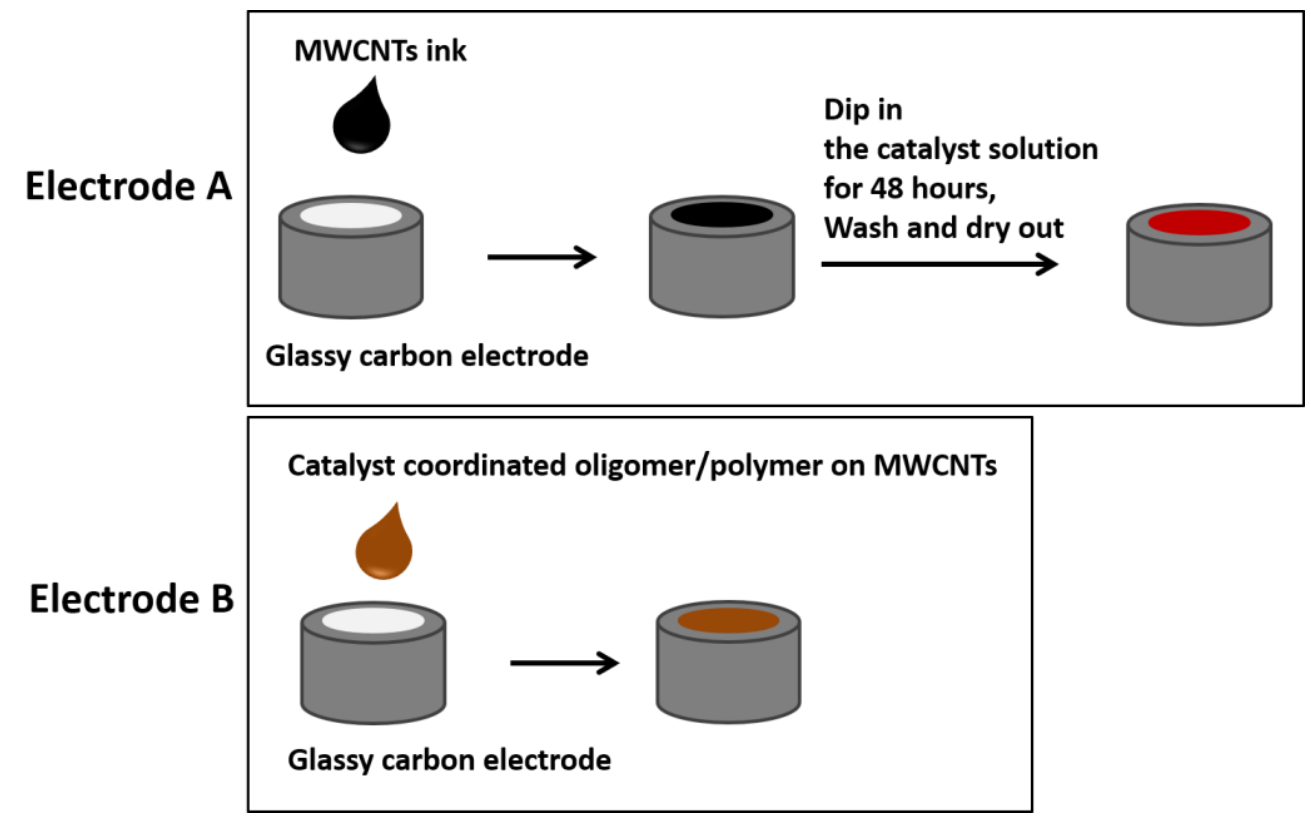

Scheme 1. Illustration of the preparation procedure for electrodes A and B.

To prevent detachment and increase the catalyst's loading, MWCNTs were added as supporting material onto the glassy carbon (GC) electrodes. Two types of electrodes (type A and B) were prepared as illustrated in Scheme 1. Briefly, electrodes of type A were prepared by drop-casting MWCNTs onto the GC electrodes, followed by dipping of them into a $\mathrm{H}_{2} \mathrm{O} / \mathrm{DMSO}$-solution of catalyst 2 for $24 \mathrm{~h}$. Type B electrodes were prepared by first attaching catalyst 2 onto the MWCNTs in THF solution, followed by drop casting onto the GC electrodes. Both type A and B electrodes were thoroughly washed with $\mathrm{EtOH}$ and $\mathrm{H}_{2} \mathrm{O}$ and dried under high flow of $\mathrm{N}_{2}$ prior to further use as described in SI. 

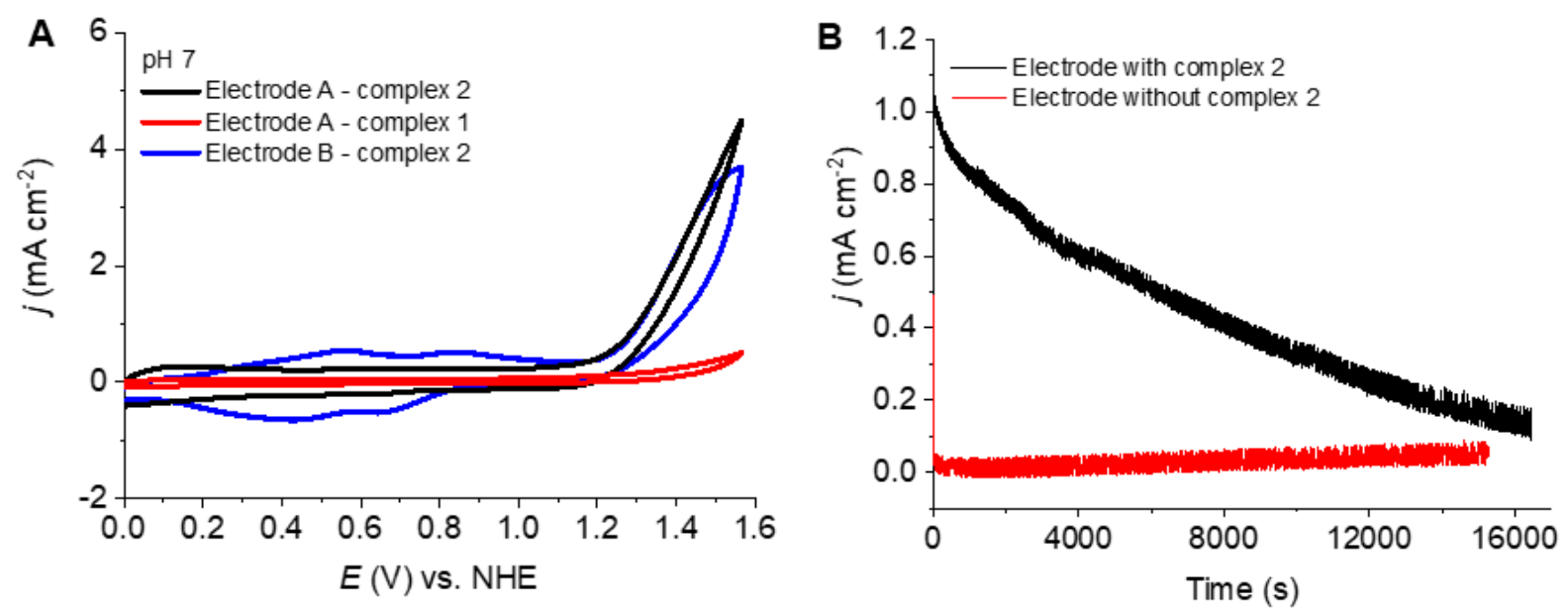

Figure 3. (A) CVs of electrodes A or B as the working electrodes (WE) in a pH 7.0 phosphate buffer solution. Scan rate is $100 \mathrm{mV} / \mathrm{s}$. A Pt disk and an $\mathrm{Ag} / \mathrm{AgCl}$ were used as counter electrode and reference electrode, respectively. (B) Bulk electrolysis using type A electrode with catalyst $\mathbf{2}$ as working electrode (black) and without catalyst $\mathbf{2}$ (red) in a phosphate buffered solution at $\mathrm{pH} 7.0$ at the potential of $1.4 \mathrm{~V}$ vs NHE.

Figure $3 \mathrm{~A}$ shows the cyclic voltametric features of electrodes $\mathrm{A}$ and $\mathrm{B}$ at $\mathrm{pH}$ 7.0. The red trace, which is the type A electrode, prepared from 1, shows almost no catalytic activity. In contrast, the black trace which comes from the same type (A) of electrode prepared from 2 , shows appreciable catalytic current starting at around 1.25 V vs. NHE. This result indicates that $\mathbf{2}$ was attached to the MWCNTs electrodes under these reaction conditions while $\mathbf{1}$ was not. The reason could be improved electrostatic interaction and $\pi$-stacking. Electrode B (blue trace) shows very similar onset potential for the electrocatalytic current associated with water oxidation at around $1.25 \mathrm{~V}$ vs. NHE, but a slightly lower electrocatalytic response compared to electrode A. However, the current density of electrode B is significantly higher than that of electrode $\mathrm{A}$ in the region of 0.2 to $1 \mathrm{~V}$ vs. NHE, which indicates higher catalyst loading for the electrode B.

The catalytic efficiency of the best performing electrode (type A, loaded with 2) was further investigated by bulk electrolysis experiments at an applied potential of $1.4 \mathrm{~V}$ vs. NHE for over $4 \mathrm{~h}$ (Figure 3B). The current steadily decreased to close to 0 after $4.5 \mathrm{~h}$ of continuous electrolysis, which is similar to other related state-of-the-art electrocatalytic systems. ${ }^{18,23}$ Looking at the current densities of electrodes A and B with 2 (Figure 3B and Figure S6B), it is quite clear that electrode A starts oxidizing water with much higher current density, but deactivates faster than electrode B. Nearly a two-fold increase of the current density was 
observed during the first 5,000 seconds, followed by a slight decrease (Figure S6B) before reaching a constant current for electrode B with 2 . This result points towards possible structural changes of the catalyst or the surface morphology under the oxidative conditions of bulk electrolysis. Altogether, it can be inferred that although the loading is much higher for electrode B, the morphology of the catalyst on MWCNTs is not suitable for higher current density.

In order to characterize the electrodes further, a series of spectroscopic studies were performed, which included scanning electron microscopy (SEM), transmission electron microscopy (TEM), Fourier transform infrared spectroscopy (FTIR), Raman spectroscopy, and X-ray photoelectron spectroscopy (XPS).

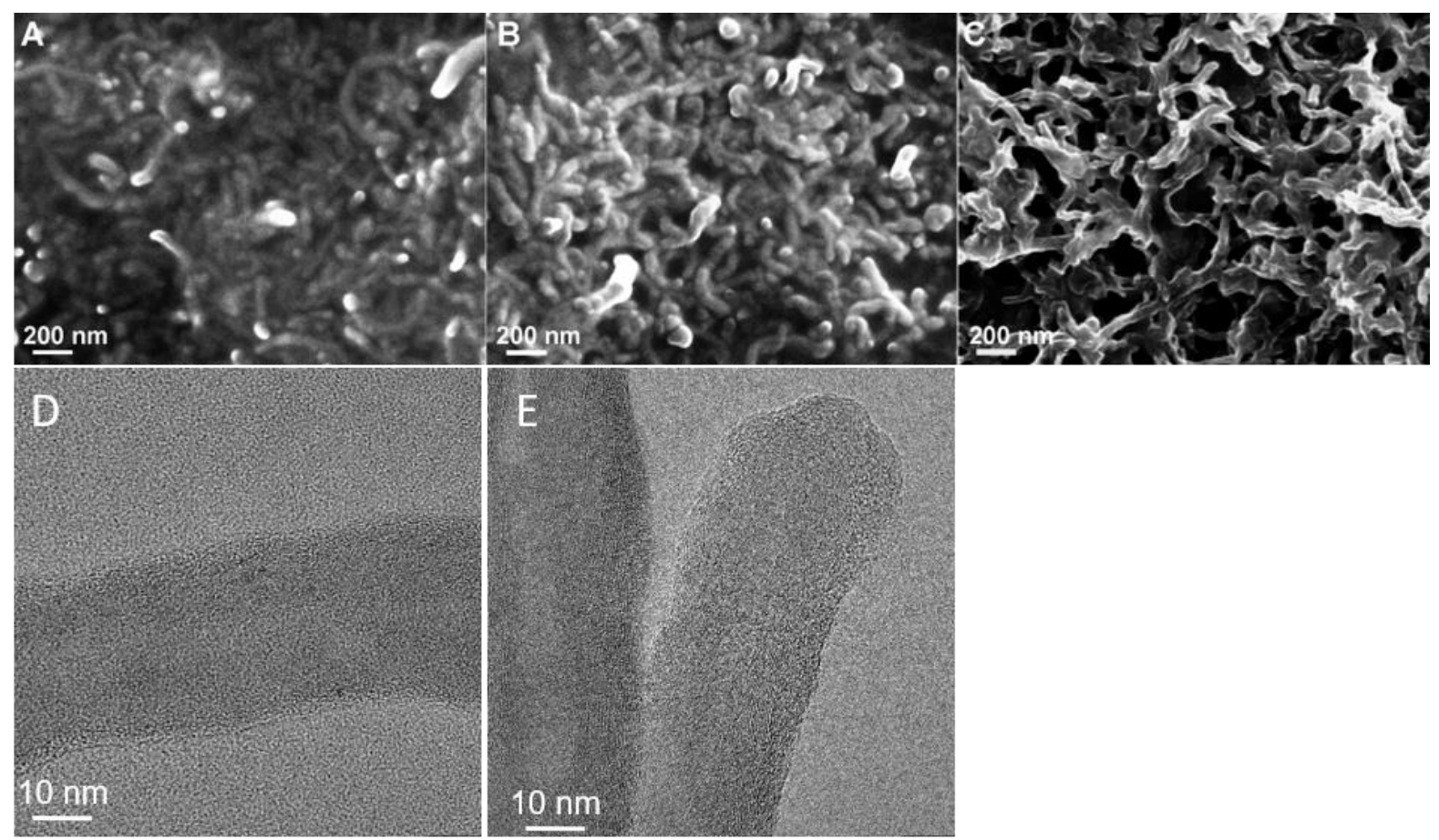

Figure 4. Scanning electron microscopy (SEM) images of (A) MWCNTs, (B) electrode type A with 2, and (C) electrode type B with 2. Transmission electron microscopy (TEM) images of (D) electrode type A with $\mathbf{2}$ and (E) electrode type B with $\mathbf{2}$

In order to correlate the electrochemical behavior of electrodes $\mathrm{A}$ and $\mathrm{B}$ with the preparation procedure, the surface morphology of the two electrodes as well as an electrode prepared from pure MWCNTs were examined by SEM and TEM (Figure 4). The SEM image of MWCNTs (Figure 4A) shows that the carbon nanotubes have a diameter around $20 \mathrm{~nm}$ and length close to $200 \mathrm{~nm}$. For electrode A, a smooth and uniformly covering layer of 2 on the 
MWCNTs is observed (Figure 4B). The thickness of the MWCNTs is around $30 \mathrm{~nm}$, reflecting an excellent attachment of $\mathbf{2}$ onto the surface of the MWCNTs. In contrast, electrode B (Figure 4C) with 2 displays an irregular coating of around $30 \mathrm{~nm}$ on the MWCNTs that causes them to agglomerate. These results indicate that the catalyst could evenly cover the MWCNTs on the surface of electrode A, while catalyst-coated MWCNTs are randomly interconnected on the surface of electrode B. Further visualization of individual carbon nanotubes was provided by high resolution TEM micrographs. From these, it can be seen that both electrodes A and B show the presence of hollow channels with the orientation of graphene layers, which is the typical appearance of the MWCNTs with the diameter of approximately $30 \mathrm{~nm}$. It can also be noticed that the outside of the crystalline lattice of the MWCNTs is covered by amorphous materials for electrode B (Figure 4E), while this cannot be seen for electrode A (Figure 4D). On the other hand, the aggregation of catalyst 2 can rarely be seen for electrode A. These observations suggest that the 4,4'-bipyridine unit facilitate absorption of catalyst $\mathbf{2}$ onto the surface of MWCNTs, most likely via improved $\pi$-stacking and electrostatic interactions.

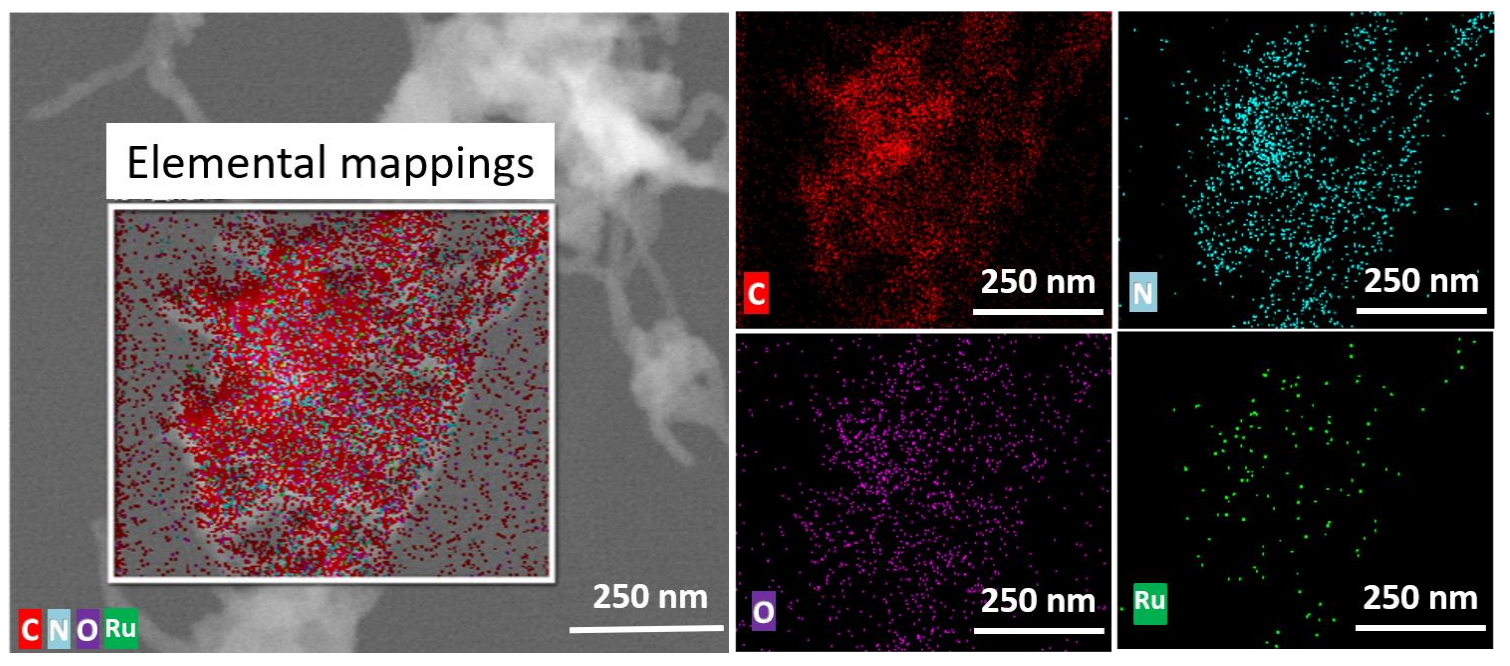




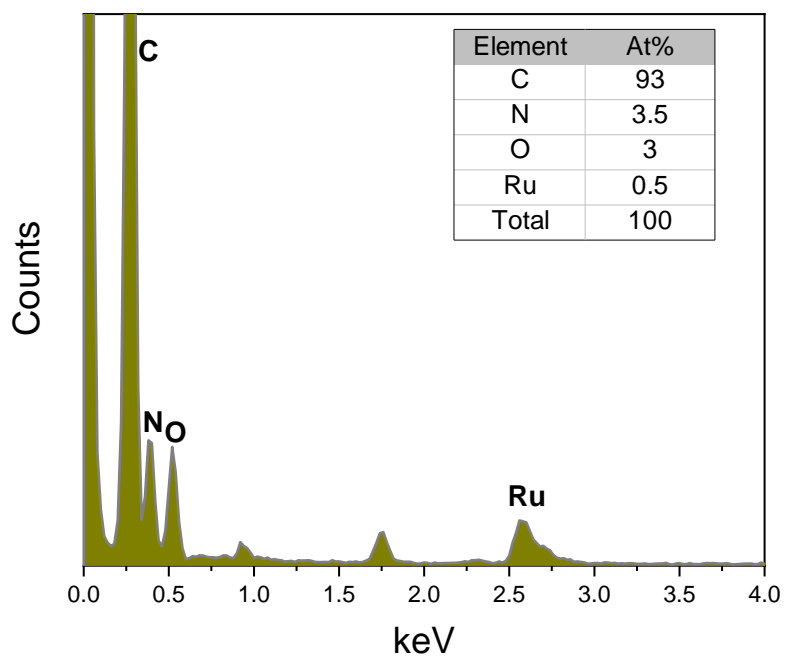

Figure 5. Scanning transmission electron microscopy (STEM) image of electrode type B with $\mathbf{2}$ and corresponding elemental mappings using energy dispersive X-ray spectroscopy (EDS).

In order to further verify the catalysts coverage on MWCNTs, TEM combined with EDX were used to explore the elemental composition of the electrodes. The elemental mappings of $\mathrm{C}, \mathrm{N}, \mathrm{O}$, and $\mathrm{Ru}$ in electrode $\mathrm{B}$ are presented in Figure 5. From this result, it can be seen that the atomic ratio between $\mathrm{N}$ and $\mathrm{Ru}$ is around $7: 1$, which is in agreement with the expected composition of catalyst 2 . Unfortunately, we were unable to estimate the elemental composition of electrode A, due to the low loading of catalyst 2 (Figure S9).
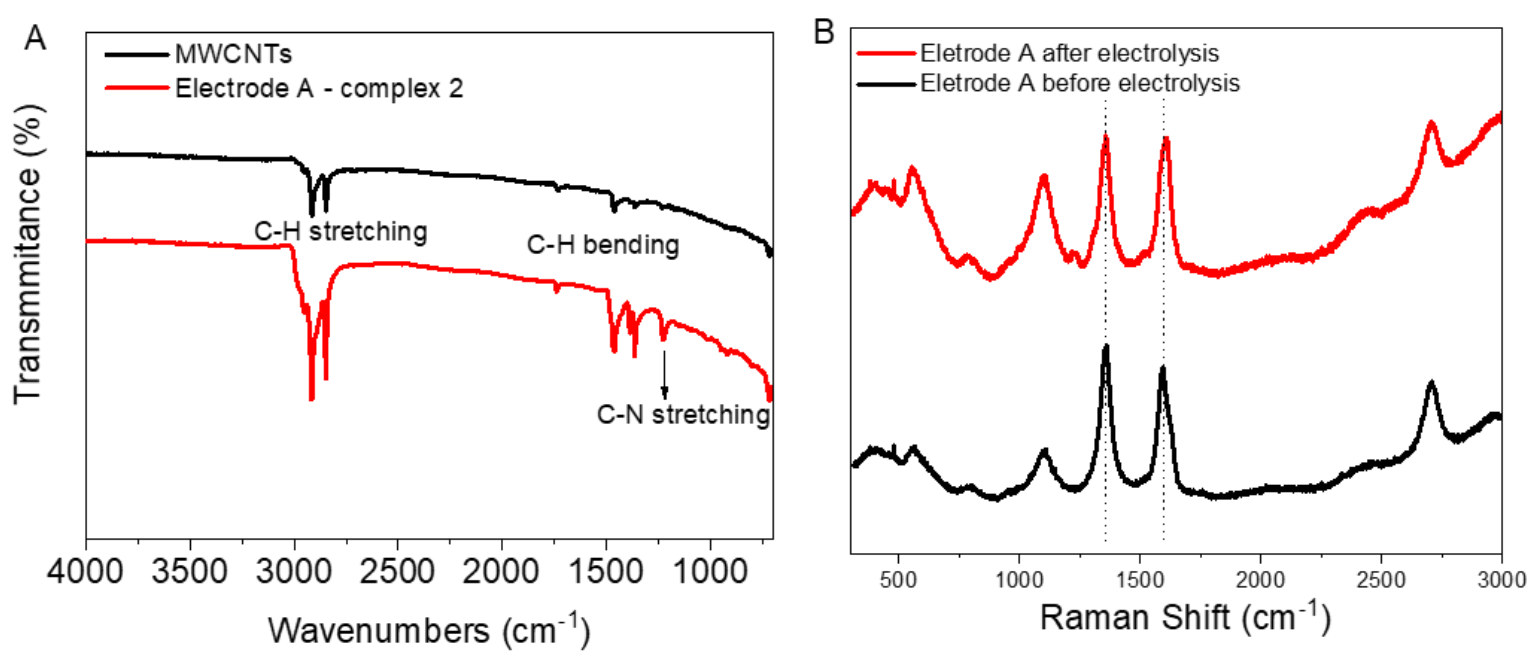

Figure 6. (A) FTIR spectra of electrode A and MWCNTs. (B) Raman spectral analysis of MWCNTs and electrode A with $\mathbf{2}$ before and after electrolysis. 
FTIR and Raman spectroscopy confirmed the molecular level attachment of the complexes to the MWCNTs as observed by electron microscopy. The FTIR spectra of electrode A and MWCNTs are shown in Figure 6A. Both MWCNTs and catalyst-coated MWCNTs on electrodes show characteristics C-H stretching $\left(2955-2840 \mathrm{~cm}^{-1}\right)$ and $\mathrm{C}-\mathrm{H}$ bending $\left(1465-1360 \mathrm{~cm}^{-1}\right)$ bands. A relatively stronger intensity of the stretching and bending bands of $\mathrm{C}-\mathrm{H}$ from the complex coating on electrode implies the cumulative signals from the $\mathrm{C}-\mathrm{H}$ moieties of MWCNTs and the catalyst 2 . In addition, the band at $1227 \mathrm{~cm}^{-1}$ can be assigned to the $\mathrm{C}-\mathrm{N}$ stretching of pyridine, further emphasizing the successful attachment of 2 on the MWCNTs. A very weak band centered at $1730 \mathrm{~cm}^{-1}$ is observed for both MWCNTs and catalyst-coated electrode, which could correspond to stretching of $\mathrm{C}=\mathrm{O}$ from surface groups on the MWCNTs and from 2 that coats the electrode. The Raman spectra of electrode A before and after electrolysis were compared (Figure 6B). The major peaks are from the $G$ and D bands of MWCNTs, which are associated with in-plane vibration modes. ${ }^{30}$ It can be explained by the low loading of the catalyst. A slight rise of the signal around $1106 \mathrm{~cm}^{-1}$ after electrolysis experiments indicates possible small structural changes of the catalyst during the electrolysis process. No characteristic Raman spectral features of $\mathrm{RuO}_{2}$, such as a sharp peak located around 515 to $528 \mathrm{~cm}^{-1}$ (due to the $\mathrm{E}_{\mathrm{g}}$ of $\mathrm{RuO}_{2}$ ) could be observed. ${ }^{31}$ Thus, there was no evidence of formation of $\mathrm{RuO}_{2}$ during the electrolysis based on the Raman spectral analysis. 

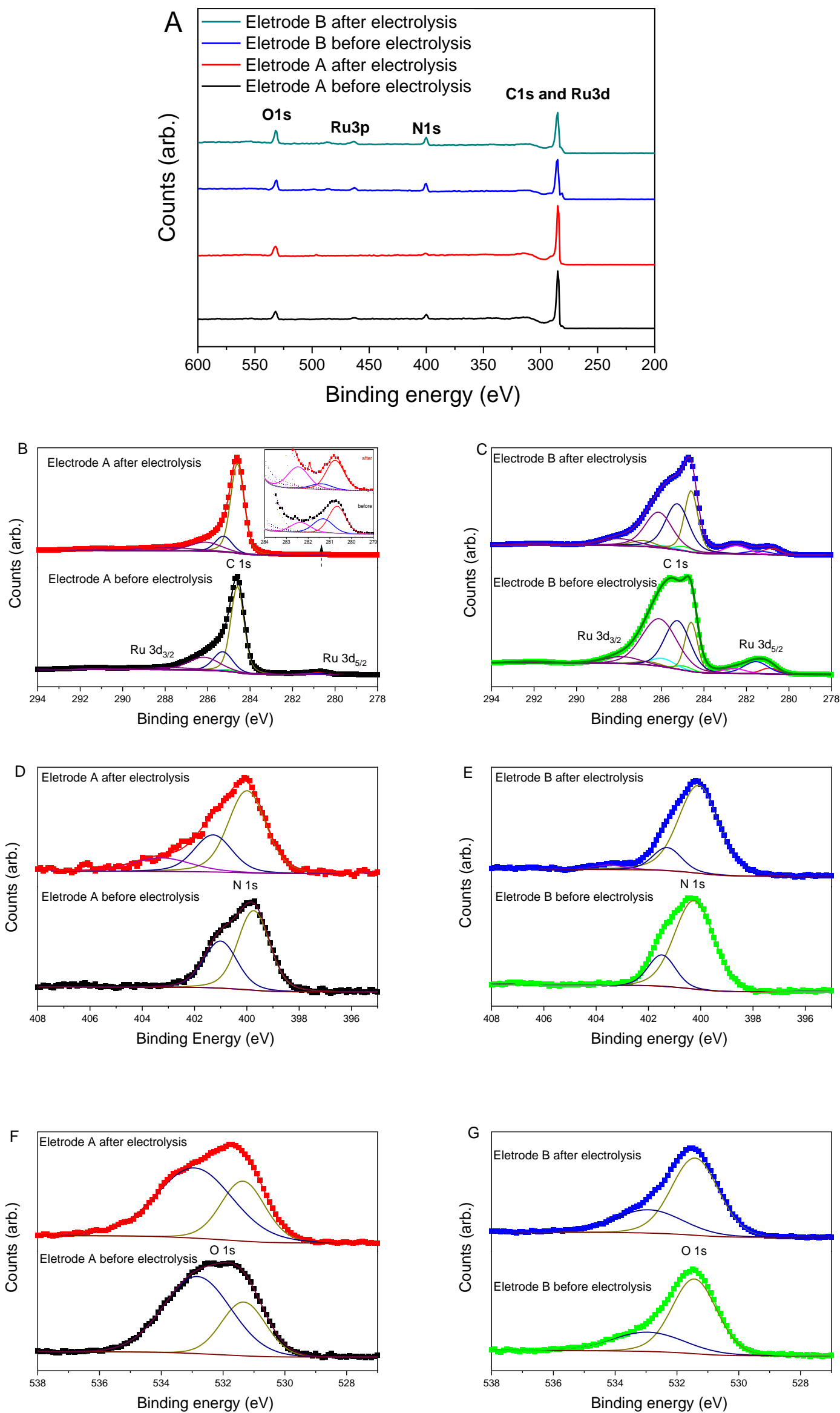
Figure 7. (A) The full XPS spectra of electrode A and electrode B before and after electrolysis. The high-resolution scan for (B) and (C) C 1s and Ru 3d, (D) and (E) N 1s, (F) and $(\mathrm{G}) \mathrm{O}$ 1s of electrode $\mathrm{A}$ and electrode $\mathrm{B}$ before and after electrolysis.

Furthermore, XPS was used to investigate the elemental composition and chemical state of the electrode material before and after the electrocatalysis (Figure 7 and Figure S8). The full XPS spectra of electrodes A and B before and after electrolysis show the existence of C, $\mathrm{N}, \mathrm{Ru}$, and $\mathrm{O}$ (Figure 7A). High-resolution XPS spectra for $\mathrm{C} 1 \mathrm{~s}$ and Ru3d are shown in Figure $7 \mathrm{~B}$ and $7 \mathrm{C}$, wherein the $\mathrm{C} 1 \mathrm{~s}$ peak at $284.6 \mathrm{eV}$ is from the $\mathrm{C}-\mathrm{C}$ of the graphite overlapping with $\mathrm{Ru} 3 \mathrm{~d}_{3 / 2}$ at $288 \mathrm{eV}$ whereas the peak at $281 \mathrm{eV}$ corresponds to $\mathrm{Ru} 3 \mathrm{~d}_{5 / 2}$. Curve fitting of the $\mathrm{Ru} 3 \mathrm{~d}$ and $\mathrm{C} 1 \mathrm{~s}$ core level peaks was performed to isolate the contribution of the different species. More than three types of carbon were found from the peaks centering around $284.6,285.3$, and $286.1 \mathrm{eV}$, which is proposed to be $\mathrm{C}-\mathrm{C}$ of the graphite peak and $\mathrm{C}-$ $\mathrm{C}, \mathrm{C}-\mathrm{N}$, and $\mathrm{C}=\mathrm{O}$ of the catalytic material 2 . There were no significant changes regarding the positions of the carbons except for the intensity of the different species. In other words, the peak positions before and after electrolysis are consistent, which indicates that no new or structurally very different species are being formed upon electrolysis. The change in proportion of the species before and after electrolysis might be due to the activation of materials during the water oxidation reaction. For instance, more $\mathrm{Ru}^{2+}$ species were converted to $\mathrm{Ru}^{3+}$ species. It can also be noticed that the intensity of the peak at $281 \mathrm{eV}\left(\mathrm{Ru} 3 \mathrm{~d}_{5 / 2}\right)$ is weaker for the electrodes after electrolysis. The weaker signal indicates lower quantities of ruthenium-based materials, which might be due to the slow loss of ruthenium-based material during the electrolysis process. Therefore, the lack of $\mathbf{2}$ on the electrode might be the reason for the reduction of current density when continuous electrolysis was carried out as shown in Figure 3. The peak intensities of both $\mathrm{Ru} 3 \mathrm{~d}_{3 / 2}$ and $\mathrm{Ru} 3 \mathrm{~d}_{5 / 2}$ are much higher for electrode $\mathrm{B}$ (Figure 7(C)) than for electrode A (Figure 7(B)). This can again be attributed to the higher loading of the catalyst in electrode B. Figure 7(D) and (E) show the high-resolution scan for the $\mathrm{N}$ 1s. All the spectra show clear $\mathrm{N}$ 1s peaks, which indicate the existence of ligands containing $\mathrm{N}$ in both types of electrodes before and after the electrolysis process. New peaks at higher binding energy were found after the electrolysis that indicates the presence of a more highly oxidized environment around $\mathrm{N}$. This is most likely due to a high oxidation state of the metal center of the molecular catalysts. Figure $7(\mathrm{~F})$ and $(\mathrm{G})$ show the high-resolution scan for the $\mathrm{O} 1 \mathrm{~s}$. All the spectra show similar peak positions, although different electrodes show different proportions of the two species. Also here, the peak positions are more or less 
identical for the electrode before and after electrolysis, which indicates the presence of molecular catalysts rather than ruthenium oxide before and after the electrolysis.

In summary, we report on a molecular Ru catalyst, which was modified from our previously published highly active ruthenium-based water oxidation catalyst $\left(\left[\mathrm{Ru}(\mathrm{mcbp})(\mathrm{py})_{2}\right]\right)$ by replacing the pyridines with 4,4'-bipyridine units. This catalyst was anchored onto the surface of MWCNTs using two different methods, which both form highly active electrodes for electrochemically driven water oxidation. These electrodes were characterized by SEM, TEM, EDX, FTIR, Raman, and XPS before and after electrolysis, and interestingly no sign of $\mathrm{RuO}_{2}$ formation was detected during the electrocatalysis, demonstrating the high stability of the catalyst on MWCNTs. While this article was being prepared, we became aware that similar work had been carried out with a different catalyst by the Llobet's group, which had a similar efficiency and stability as ours. ${ }^{32}$ However, it is important to point out that the catalyst reported in the current work operates at even lower potential than that one prepared by the Llobet's group. This demonstrates the positive influence of the non-innocent imidazole ligand on the electrolytic (electro-catalytic) water oxidation. Furthermore, it shows that proper utilization of the imidazole unit in water oxidation electrocatalysts and in the manufacture of anodes for electrolysis cells can be a viable strategy for the future. Both electrodes A and B are clearly very efficient and taken together, our results suggest that such high-performance systems can very well compete with oxide-based electrodes in commercial applications in the future.

\section{Acknowledgements}

We thank Futura Foundation for the financial support. BD and B $\AA$ acknowledge the computational facilities from Swedish National Infrastructure [Computational time (SNIC 2020/13-64) awarded to BD]. LL, PC, ZY and TW thank National Natural Science Foundation of China for the financial support (NSFC-21727801) and are grateful for the support from the Analytical Instrumentation Center (\#SPST-AIC 10112914), SPST, ShanghaiTech University. We appreciate Lars Eriksson and Erik Svensson Grape at department of materials and environmental chemistry at Stockholm University, Sweden for the trials with our samples for the single-crystal X-ray diffraction. We thank Jonas Ståhle at department of organic chemistry at Stockholm University, Sweden for the help with the ESIHRMS measurements. 


\section{References}

1. Heller, A., Hydrogen-Evolving Solar Cells. Science 1984, 223 (4641), 1141.

2. Yamamoto, M.; Tanaka, K., Artificial Molecular Photosynthetic Systems: Towards Efficient Photoelectrochemical Water Oxidation. ChemPlusChem 2016, 81 (10), 1028-1044.

3. Seh, Z. W.; Kibsgaard, J.; Dickens, C. F.; Chorkendorff, I.; Nørskov, J. K.; Jaramillo, T. F., Combining theory and experiment in electrocatalysis: Insights into materials design. Science 2017, 355 (6321), eaad4998.

4. Kärkäs, M. D.; Verho, O.; Johnston, E. V.; Åkermark, B., Artificial Photosynthesis: Molecular Systems for Catalytic Water Oxidation. Chemical Reviews 2014, 114 (24), 11863 12001.

5. Das, B.; Thapper, A.; Ott, S.; Colbran, S. B., Structural features of molecular electrocatalysts in multi-electron redox processes for renewable energy - recent advances. Sustainable Energy \& Fuels 2019, 3 (9), 2159-2175.

6. Ashford, D. L.; Gish, M. K.; Vannucci, A. K.; Brennaman, M. K.; Templeton, J. L.; Papanikolas, J. M.; Meyer, T. J., Molecular Chromophore-Catalyst Assemblies for Solar Fuel Applications. Chemical Reviews 2015, 115 (23), 13006-13049.

7. Blakemore, J. D.; Crabtree, R. H.; Brudvig, G. W., Molecular Catalysts for Water Oxidation. Chemical Reviews 2015, 115 (23), 12974-13005.

8. Hunter, B. M.; Gray, H. B.; Müller, A. M., Earth-Abundant Heterogeneous Water Oxidation Catalysts. Chemical Reviews 2016, 116 (22), 14120-14136.

9. McCrory, C. C. L.; Jung, S.; Peters, J. C.; Jaramillo, T. F., Benchmarking Heterogeneous Electrocatalysts for the Oxygen Evolution Reaction. J. Am. Chem. Soc. 2013, 135 (45), 16977-16987.

10. Berardi, S.; Drouet, S.; Francàs, L.; Gimbert-Suriñach, C.; Guttentag, M.; Richmond, C.; Stoll, T.; Llobet, A., Molecular artificial photosynthesis. Chemical Society Reviews 2014, 43 (22), 7501-7519.

11. Garrido-Barros, P.; Gimbert-Suriñach, C.; Matheu, R.; Sala, X.; Llobet, A., How to make an efficient and robust molecular catalyst for water oxidation. Chemical Society Reviews 2017, 46 (20), 6088-6098.

12. Mamaca, N.; Mayousse, E.; Arrii-Clacens, S.; Napporn, T. W.; Servat, K.; Guillet, N.; Kokoh, K. B., Electrochemical activity of ruthenium and iridium based catalysts for oxygen evolution reaction. Applied Catalysis B: Environmental 2012, 111-112, 376-380.

13. Gil-Sepulcre, M.; Lindner, J. O.; Schindler, D.; Velasco, L.; Moonshiram, D.; Rüdiger, O.; DeBeer, S.; Stepanenko, V.; Solano, E.; Würthner, F.; Llobet, A. Surface-Promoted Evolution of Ru-bda Coordination Oligomers Boosts the Efficiency of Water Oxidation Molecular Anodes. J. Am. Chem. Soc. 2021, 143, 11651-11661.

14. Yang, J.; Wang, L.; Zou, H.; Chen, H.; Ahlquist, M. S. G.; Duan, L.; Sun, L. From Rubda to Ru-bds: a step forward to highly efficient molecular water oxidation electrocatalysts under acidic and neutral conditions. Nat. Commun. 2021, 12, 373.

15. Shatskiy, A.; Bardin, A. A.; Oschmann, M.; Matheu, R.; Benet-Buchholz, J.; Eriksson, L.; Kärkäs, M. D.; Johnston, E. V.; Gimbert-Suriñach, C.; Llobet, A.; Åkermark, B., Electrochemically Driven Water Oxidation by a Highly Active Ruthenium-Based Catalyst. ChemSusChem 2019, 12 (10), 2251-2262.

16. Costentin, C.; Drouet, S.; Robert, M.; Savéant, J.-M., Turnover Numbers, Turnover Frequencies, and Overpotential in Molecular Catalysis of Electrochemical Reactions. Cyclic Voltammetry and Preparative-Scale Electrolysis. J. Am. Chem. Soc. 2012, 134 (27), $11235-$ 11242 . 
17. Matheu, R.; Ertem, M. Z.; Benet-Buchholz, J.; Coronado, E.; Batista, V. S.; Sala, X.; Llobet, A., Intramolecular Proton Transfer Boosts Water Oxidation Catalyzed by a $\mathrm{Ru}$ Complex. J. Am. Chem. Soc. 2015, 137 (33), 10786-10795.

18. Wang, L.; Fan, K.; Chen, H.; Daniel, Q.; Philippe, B.; Rensmo, H.; Sun, L., Towards efficient and robust anodes for water splitting: Immobilization of Ru catalysts on carbon electrode and hematite by in situ polymerization. Catalysis Today 2017, 290, 73-77.

19. Li, F.; Yang, H.; Li, W.; Sun, L., Device Fabrication for Water Oxidation, Hydrogen Generation, and CO2 Reduction via Molecular Engineering. Joule 2018, 2 (1), 36-60.

20. Chen, Z.; Concepcion, J. J.; Luo, H.; Hull, J. F.; Paul, A.; Meyer, T. J., Nonaqueous Catalytic Water Oxidation. J. Am. Chem. Soc. 2010, 132 (50), 17670-17673.

21. Hyde, J. T.; Hanson, K.; Vannucci, A. K.; Lapides, A. M.; Alibabaei, L.; Norris, M. R.; Meyer, T. J.; Harrison, D. P., Electrochemical Instability of Phosphonate-Derivatized, Ruthenium(III) Polypyridyl Complexes on Metal Oxide Surfaces. ACS Applied Materials \& Interfaces 2015, 7 (18), 9554-9562.

22. Karousis, N.; Tagmatarchis, N.; Tasis, D., Current Progress on the Chemical Modification of Carbon Nanotubes. Chemical Reviews 2010, 110 (9), 5366-5397.

23. Creus, J.; Matheu, R.; Peñafiel, I.; Moonshiram, D.; Blondeau, P.; Benet-Buchholz, J.; García-Antón, J.; Sala, X.; Godard, C.; Llobet, A., A Million Turnover Molecular Anode for Catalytic Water Oxidation. Angewandte Chemie International Edition 2016, 55 (49), 1538215386.

24. Li, F.; Li, L.; Tong, L.; Daniel, Q.; Göthelid, M.; Sun, L., Immobilization of a molecular catalyst on carbon nanotubes for highly efficient electro-catalytic water oxidation. Chem. Commun. 2014, 50 (90), 13948-13951.

25. Maurin, A.; Robert, M., Noncovalent Immobilization of a Molecular Iron-Based Electrocatalyst on Carbon Electrodes for Selective, Efficient CO2-to-CO Conversion in Water. J. Am. Chem. Soc. 2016, 138 (8), 2492-2495.

26. Li, F.; Zhang, B.; Li, X.; Jiang, Y.; Chen, L.; Li, Y.; Sun, L., Highly Efficient Oxidation of Water by a Molecular Catalyst Immobilized on Carbon Nanotubes. Angewandte Chemie International Edition 2011, 50 (51), 12276-12279.

27. Schindler, D.; Gil-Sepulcre, M.; Lindner, J. O.; Stepanenko, V.; Moonshiram, D.; Llobet, A.; Würthner, F., Efficient Electrochemical Water Oxidation by a Trinuclear Ru(bda) Macrocycle Immobilized on Multi-Walled Carbon Nanotube Electrodes. Advanced Energy Materials 2020, 10 (43), 2002329.

28. Grimme, S.; Ehrlich, S.; Goerigk, L., Effect of the damping function in dispersion corrected density functional theory. Journal of Computational Chemistry 2011, 32 (7), 14561465 .

29. Biradha, K.; Sarkar, M.; Rajput, L., Crystal engineering of coordination polymers using 4,4'-bipyridine as a bond between transition metal atoms. Chem. Commun. 2006, (40), 41694179 .

30. Nisha, B.; Vidyalakshmi, Y.; Abdul Razack, S., Enhanced formation of ruthenium oxide nanoparticles through green synthesis for highly efficient supercapacitor applications. Advanced Powder Technology 2020, 31 (3), 1001-1006.

31. Mar, S. Y.; Chen, C. S.; Huang, Y. S.; Tiong, K. K., Characterization of RuO2 thin films by Raman spectroscopy. Applied Surface Science 1995, 90 (4), 497-504.

32. Hoque, M. A.; Gil-Sepulcre, M.; de Aguirre, A.; Elemans, J. A. A. W.; Moonshiram, D.; Matheu, R.; Shi, Y.; Benet-Buchholz, J.; Sala, X.; Malfois, M.; Solano, E.; Lim, J.; Garzón-Manjón, A.; Scheu, C.; Lanza, M.; Maseras, F.; Gimbert-Suriñach, C.; Llobet, A., Water oxidation electrocatalysis using ruthenium coordination oligomers adsorbed on multiwalled carbon nanotubes. Nat Chem 2020, 12 (11), 1060-1066. 
33. Dulière, E.; Devillers, M.; Marchand-Brynaert, J., Novel Phosphinite-Ruthenium(II) Complexes Covalently Bound on Silica: Synthesis, Characterization, and Catalytic Behavior versus Oxidation Reactions of Alcohols into Aldehydes. Organometallics 2003, 22 (4), 804811.

34. Weigend, F.; Ahlrichs, R., Balanced basis sets of split valence, triple zeta valence and quadruple zeta valence quality for $\mathrm{H}$ to $\mathrm{Rn}$ : Design and assessment of accuracy. Physical Chemistry Chemical Physics 2005, 7 (18), 3297-3305. 